\title{
BALL-THROMBUS OF THE RIGHT ATRIUM
}

\author{
BY \\ EVA FROMMER \\ From the Whittington Hospital, Highgate, London
}

\begin{abstract}
A study of reported cases reveals that while the occurrence of ball-thrombus of the left atrium is unusual a ball-thrombus of the right atrium is very rare indeed. The first case report is that of McLeod, in 1883, and sixty-one years elapse before the next-that of Wright, Flynn, and Druet, in 1944. Radding in America and Moia et al. in Argentina each published a report of a case in 1951, and the latter refer to an unpublished thesis by Romano of Buenos Aires (1944), in which a further case is described. As only five examples have apparenty been reported up to the present, it is thought of interest to record a sixth. On correlating the histories and clinical findings, a distinct picture emerges; indeed, it may be possible to make an ante-mortem diagnosis of ball valve obstruction of the tricuspid valve, as actually occurred in the case of Wright et al. (1944); whether or not it is due to a thrombus, however, and whether this thrombus is free or attached, cannot be clinically ascertained.
\end{abstract}

\section{Case Report}

The patient, a woman of 69 , was admitted on $16 / 7 / 54$, complaining of breathlessness and nausea. She had been quite healthy in the past, apart from occasional fainting attacks and some winter bronchitis, and had had ten normal pregnancies. Five years previously she was told that she had a murmur in the heart and was given a short course of tablets. Thirteen months previously she had a severe attack of breathlessness on rising in the morning lasting three to four hours. Since this time she had been unable to lie flat. A similar attack occurred one month before admission and she had stayed in bed since this. Nausea set in two weeks, and peripheral œdema one week, before admission.

On examination she was a pale, dyspnœic, rather nervous woman. She had a regular pulse, slowly rising in quality, and marked arteriosclerosis. Her blood pressure was 190/85. The apex-beat was in the left sixth space in the anterior axillary line, and heaving in quality. There were no thrills. A rough systolic murmur was heard in the aortic area, with an early diastolic murmur of aortic regurgitation which was conducted down the left border of the sternum. There was also a loud mitral systolic murmur. The abdomen was distended, the liver not palpable, and there was pitting œedema of the legs and sacrum. In the chest there was poor air-entry, with generalized crepitations over both lower lobes, and signs of fluid at both bases, more on the right.

A diagnosis of aortic stenosis with incompetence and left ventricular failure was made.

Results of Investigations. X-ray of chest (one week after admission) : gross cardiac enlargement, unfolded and elongated aorta, right basal effusion. Radioscopy (two weeks after admission) : transverse heart, enlargement of left ventricle with full pulsation; full, kicking pulsation of tortuous aorta, no calcium seen; moderate enlargement of right ventricle; enlargement of left atrium.

Electrocardiogram. Left ventricular hypertrophy.

Treatment and Progress. The patient was put on a salt-free diet, and given digoxin, neomercazole, and mersalyl; she was also given a course of chloramphenicol. The response initially was good, except for persistent nausea, and orthopnœa. On 2/8/54 the patient had a blackout in the evening and from that time her condition deteriorated.

On several occasions she complained of throbbing in the abdomen in the evening. During one such episode there was marked distension of the peripheral veins, down to the dorsum of the hand, lasting about 
an hour, with moderate dyspnœa of air-hunger type. This symptom was not properly evaluated at the time but the patient remarked that she had noticed the venous distension before.

On 22/8/54 the right pleural effusion reappeared. On $31 / 8 / 54,580 \mathrm{ml}$. of sterile, bloodstained fluid were aspirated from the right side of the chest, there was no symptomatic relief. The patient developed a purpuric rash, became comatose, and died on 4/9/54.

Necropsy (6/9/54: Dr. S. Robinson). Ball-thrombus in right auricle; failure of hypertrophied left ventricle; calcification and stenosis of aortic valve; chronic rheumatic endocarditis.

Weight of heart 660 grammes. Foraman ovale closed. Edema, cloudy swelling, and very great hypertrophy of myocardium of left ventricle. (Left ventricle $2 \mathrm{~cm}$., right ventricle $0.5 \mathrm{~cm}$. thick.) Several discrete masses of ante-mortem thrombus (up to $1 \mathrm{~cm}$. diameter) enmeshed in columnæ carneæ at apex. Slight hypertrophy of right auricle with polypous mass $(2.5 \times 2 \times 1 \mathrm{~cm}$.) of furrowed, reddish-grey antemortem thrombus adherent to endocardium of appendix; ball-thrombus $3 \times 3 \times 2 \mathrm{~cm}$. lying free in cavity of right auricle, with irregular, partly furrowed, mottled red and white outer surface, with short projections up to $1 \mathrm{~cm}$. long, and diffluent reddish-grey centre. Severe fibrosis with calcification and stenosis of aortic valve; other valves normal. Slight atheroma of coronary arteries; severe atheroma of aorta and its branches with ante-mortem thrombus lining upper abdominal aorta and blocking coeliac axis.

The lungs showed red induration with hæmorrhagic infarction of lower lobe of right lung and ante-mortem thrombus in right pulmonary artery. Collapse and similar infarction $(2 \times 2 \mathrm{~cm}$.) in lower lobe of left lung. Hæmorrhagic effusion (500 c.c.) in the right pleural cavity.

Great congestion of abdominal organs and brain.

Massive general anasarca; ecchymoses on arms, knees, and right foot of a cyanosed, well-developed, moderately well-nourished woman.

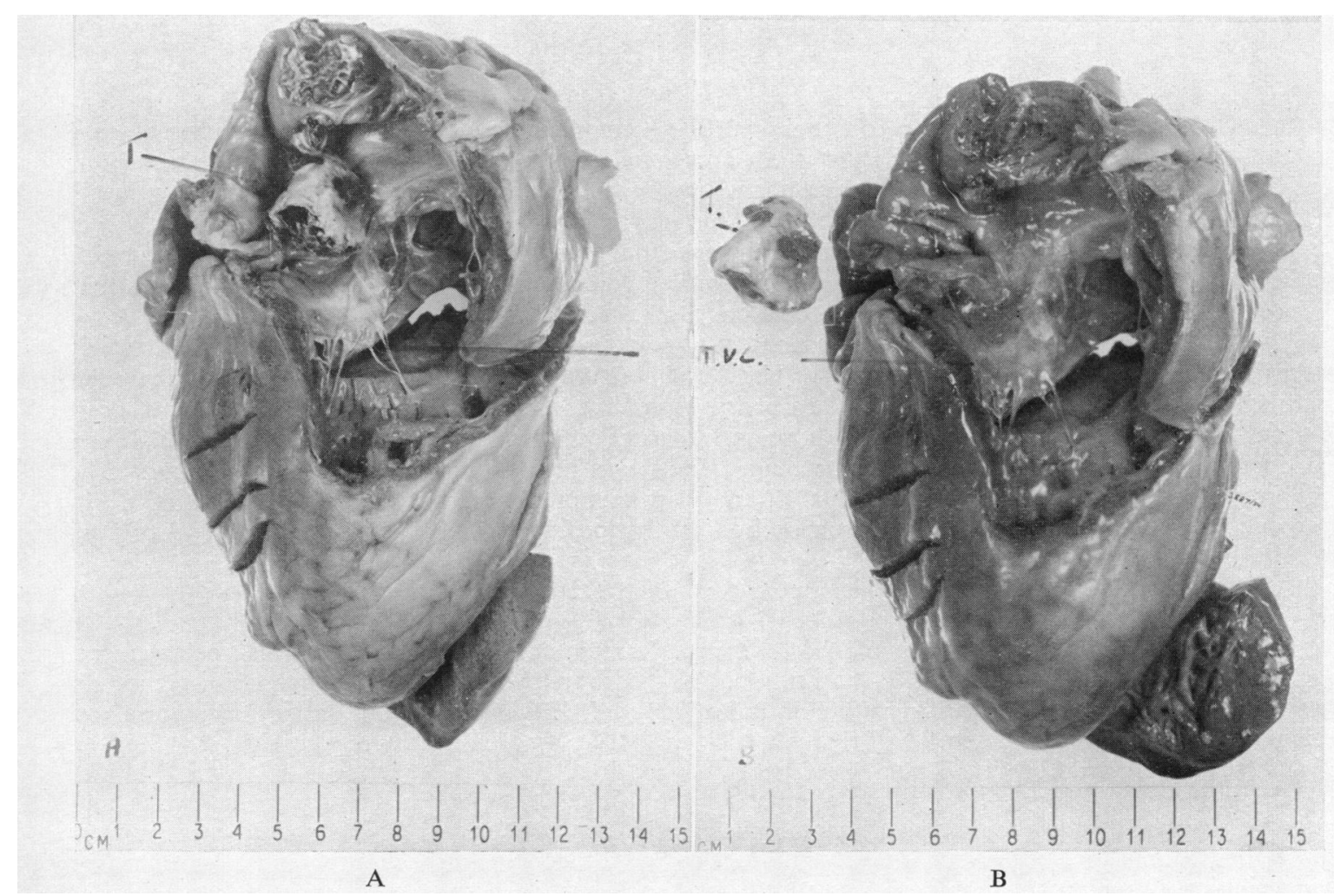

FIG. 1.-Heart opened at necropsy; right anterior wall removed. (A) Showing thrombus in situ (T). (B) Showing the detached thrombus (T) which has lost its rounded contour in fixing. The septal cusp of the tricuspid valve (TVC) is seen. 


\section{Discussion}

Wright et al. in their case report set out the criteria on which they were able-before the patient's death-to make their diagnosis of a movable embolus riding over the tricuspid valve.

A composite picture emerges from previous reports and this case, of a patient who may have a known valvular lesion, with congestive failure, or who has recently suffered a severe disease, who suddenly develops a syncopal attack without any obvious cause, and with marked air-hunger, despite a good air-entry into the chest. Severe orthopnœa develops, out of proportion to the degree of cardiac failure, and there may be pain in the chest aggravated by lying back. Intractable nausea sets in. There are attacks of dyspnœea, often accompanied by great engorgement of the peripheral veins, which even pulsate in some instances down to the long saphenous. The liver during these bouts, or at other times, becomes engorged and pulsates.

The condition is necessarily progressive, and the outcome fatal, but the mobility of the ballthrombus within the atrium causes striking variations in both symptoms and signs through its erratic behaviour. Episodes of almost complete obstruction of the pulmonary blood-flow can alternate with periods of freedom, producing rapid changes in the state of the lungs. In other cases intermittent incompetence of the valve through partial impaction of the thrombus in it, may complicate the clinical picture. The size of the thrombus and the state of the valve also affect this.

\section{Summary}

A case of ball-thrombus in the right atrium of a patient with rheumatic aortic stenosis and incompetence is described. A consideration of the symptomatology suggests that a diagnosis of this condition can be made during life, by the presence of intermittent symptoms and signs of tricuspid stenosis.

I wish to express my gratitude to Dr. H. E. S. Pearson for permission to publish this case, and for his help and encouragement and also to Dr. S. Robinson for the post-mortem report and photographs, and for valuable criticism.

\section{References}

McLeod, N. (1883). Edinburgh med. J., 28, 696.

Moia, B., Manguel, M. E., and Hojman, D. (1951). Rev. Argent. Cardiol., 18, 320.

Radding, R. S. (1951). Amer. J. Med., 11, 653.

Romano, F. J. (1944). Tesis de doctorado, Bs. Aires (Inedita).

Wright, I. S., Flynn, J. E., and Druet, K. L. (1944). Amer. Heart J., 27, 858. 